\title{
Cytomorphology of Conjunctival Epithelium in Ocular Surface Disorders
}

\author{
${ }^{1}$ Dr. Renu Sahay, ${ }^{2}$ Dr.Jitendra Kumar, ${ }^{3}$ Kanhaiya Prasad. \\ ${ }^{1}$ Associate Professor, department of Pathology, M.L.B. Medical College, Jhansi. \\ ${ }^{2}$ Associate Professor and Head department of ophthalmology, M.L.B. Medical College, Jhansi. \\ ${ }^{3}$ Junior Resident, Department of ophthalmology, M.L.B. Medical College, Jhansi
}

\begin{abstract}
Introduction: To study cytomorphological changes in various ocular surface disorders and find out the sensitivity, specificity and the diagnostic accuracy of impression cytology

Materials and Methods: sixty patients were included in this study. Out of these 60 cases, 18 cases having vitamin A deficiency (VAD), 16 cases are having vernal keratoconjunctivitis (VKC), 20 of dry eye and 6 of chemical burn. Impression cytology was performed with each patient and the results were noted. Patients were examined for goblet cell density in the form of clumping of goblet cells and degree of squamous metaplasia in terms of loss of cell cohesion, altered cell morphology and keratinisation

Results: On impression cytology, all cases of vitamin A deficiency showed loss of goblet cells and $90 \%$ showed squamous metaplasia.In case of vernal conjunctivitis showed clumping (37\%), loss of goblet cells (69\%) and squamous metaplasia (70\%). In dry eye group, severe reduction of goblet cells (70\%) with moderate to severe grade of squamous metaplasia (95\%) was seen. All cases of chemical burn showed marked reduction of goblet cells and squamous metaplasia.
\end{abstract}

Conclusion: Impression cytology was found to be good technique for diagnosing metaplastic changes in various ocular surface disorders.

Keywords: Impression cytology; Vitamin-A deficiency; Vernalkeratoconjunctivitis; Dry eye; Chemicalinjury

\section{Introduction}

The term "ocular surface" describes the entire mucosal epithelial lining bordered by the skin at the superior and inferior eyelid margins ${ }^{[1]}$. This includes the epithelium from the muco-cutaneous junction of the eyelid margin on to the back of the lids, into its reflection back over the globe, including that which covers the cornea $^{[2]}$. Ocular surface disorder is a term that includes the disease of various types of aetiology which disturbs the delicate balance between the ocular surface, the adnexa and the tear film. Clinical diagnosis of ocular surface disorder based on slit lamp examination, Schirmer's test, tear film break up time and Rose Bengal staining do not show changes at the cellular level. The histopathological features are conventionally studied by conjunctival biopsy. This procedure being invasive is not done routinely and repeated biopsies are avoided to prevent scarring and loss of limbal stem cells. Recently a filter paper technique utilising millipore cellulose acetate paper has been developed, to obtain the conjunctival impressions and study the cellular morphology ${ }^{[3]}$. It ensures good adhesion of surface epithelial cells to the biopore membrane with the result; adequate specimens are obtained in a very high percentage of cases ${ }^{[4]}$. Sensitivity of this method is high (78- 87\%); the main disadvantages of impression cytology are some loss of morphological details and poor cell yield incases of keratinizing lesions ${ }^{[5]}$. The objective of this study was to assess the various changes of ocular surface disorder with the evaluation of alterations at the cellular level in the conjunctiva, by using impression cytology and conjunctival biopsy.

\section{Methodology}

60 patients of both the sexes reporting the symptoms of discomfort and ocular irritation such as redness, pain, discharge, blurred vision, itching, watering or tearing of eye were included.All the selected patients were subjected to detailed history taking, physical examination and clinical tests. Dry eye, vernal keratoconjunctivitis, vitamin A deficiency and chemical burn, were the most common ocular surface disorder amongst subjects included in the study. Those patients who had conjunctivitis have various types of aetiologies, except allergic, and were excluded.One drop of local anesthesia (paracain) is instilled into the patient's eye. Before applyingfilter paper on the area to be sampled, excessive tear/medication should be wiped away.Now mark the surface of the paper before applying on to the ocular surface. It is important to retract the lids from the paper. At least two samples are taken from the area to be sampled depending on size of the lesion. The paper is pressed gently with a glass rod for 5-10 seconds on to the lesion and immediately transferred into a coplin jar containing $95 \%$ ethyl alcohol for fixation. The filter paper is clipped on to the glass slidekeeping the marked 
surface upward for staining. Staining is done by Haematoxylin and eosin stain. Firstly slide with filter paper is dipped in Haematoxylin followed by eosin for 30 seconds each in coplin jar.

The filter paper with cells must be completely immersed in the staining solution. Dehydration is done in coplin jar containing butyl alcohol and clearing is done in coplinjar containing equal amount of butyl alcohol and xylene.It is then left overnight in xylene for transparency of filter paper and then mounted in Eukitt mounting media with surface containing cells facing upwards. The slides are then examined under light microscopy by an experienced ocular pathologist.On the basis of goblet cell density and distribution and also various parameters of squamous metaplasia we find different grades of cytological changes of conjunctiva in conjunctival impression cytology. ${ }^{[6]}$

\section{Grade 0 (Normal):}

a. Abundant goblet cell numbers.

b. Good cell cohesion in the form of tight epithelial sheets.

c. Nucleo-cytoplasmic ratio (N:C) 1:2 along with small rounded epithelial cells.

d. Absence of keratinisation.

\section{Grade 1 (Low normal):}

a. Mild reduction of goblet cell numbers

b. Loose cell cohesion in the form of clusters

c. Nucleo-cytoplasmic ratio (N:C) 1:3 to 1:4 along with moderately enlarged cell size.

d. Mild keratinisation.

\section{Grade 2 (Borderline):}

a. Moderate reduction of goblet cell.

b. Scattered cells with occasional clusters of loose cell cohesion.

c. Nucleo-cytoplasmic ratio $(\mathrm{N}: \mathrm{C})>1: 5$ along with enlarged cell in size and polygonal in shape.

d. Moderate keratinization.

\section{Grade 3 (Abnormal):}

a. Occasional presence or absence of goblet cell.

b. Isolated cells with complete loss of cell cohesion.

c. Anucleated cell or cell with pyknotic nuclei.

d. Severe keratinisation.

\section{Result And Discussion}

Vitamin A Deficiency (VAD)- eighteen out of 60 patients clinically had features of Vitamin Adeficiency. There were 6 (33\%)females and $12(66 \%)$ males. Mean age was 104.15. All patients ofvitamin A deficiency showed occasional presence of gobletcell with mucin spot, patients also showed complete absence of gobletcells. But presence of adequate number of goblet cell was not seen inany patient and, along with the absence of goblet cells, all cells were scattered in clusters with few cell cohesion to isolated in distributionwith complete loss of cell cohesion. Maximum patients showed moderate to severe grade change in $\mathrm{N}: \mathrm{C}$ ratio. While 2/18 (11\%)patients showed 1:2 to 1:3 N:C ratio and 10/18 (55\%) patients had moderate to severe grade presence of keratinisation. OnConjunctival biopsy, all patients of this group shows absence of gobletcells, all cells were scattered in clusters with few cell cohesion to isolatein distribution with complete loss of cell cohesion. Maximum patients showed moderate to severe grade change in $\mathrm{N}: \mathrm{C}$ ratio. While $2 / 18(11 \%)$ patients showed 1:2 to $1: 3 \mathrm{~N}: \mathrm{C}$ ratio and $10 / 18(55 \%)$ patients had moderate to severe grade presence of keratinisation .Vernal keratoconjunctivitis (VKC) group - Out of 16 patients, four $(25 \%)$ were female and twelve $(75 \%)$ were male in this group with mean age of 161 months. Goblet cell count was abundant in 6/16(37.50\%) patients and moderate cell count was seen in 3/18.(75\%)patients, which were present in clump.

Occasional presenceof goblet cell was seen in 8/16 (50\%) cases while only 5/16 (31.25\%)patients showed complete absence of goblet cell. Patients in early stageof disease had clumping of goblet cells along with abundant gobletcells. 5/16 (31.25\%) patients showed tight epithelial sheet without any loss of cohesion while $11 / 16(68.75 \%)$ patients showed moderate to severe loss of cell cohesion. Keratinisation was completely absent in 10/16 (62.50\%) patients and 5/16 (31.25\%) patients showed moderate grade presence of keratinisation. thirteen patients $(78 \%)$ had $\mathrm{N}: \mathrm{C}$ 

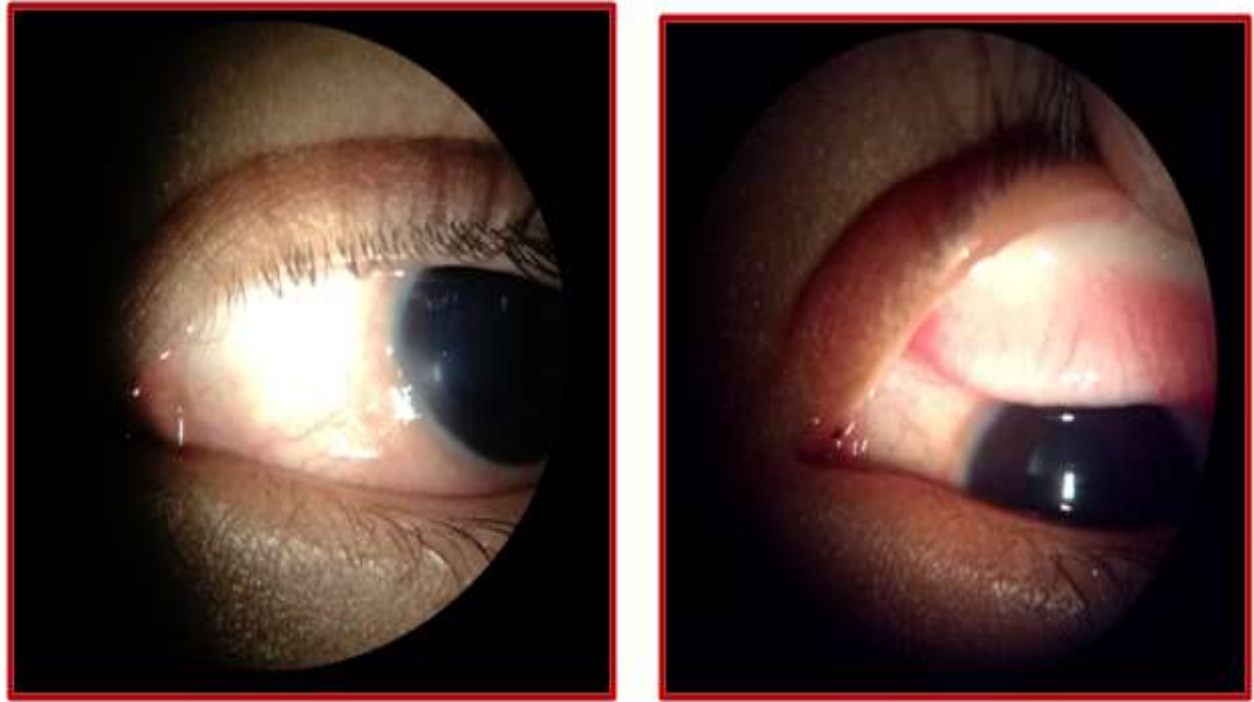

Vernal Keratoconjunctivitis (VKC)

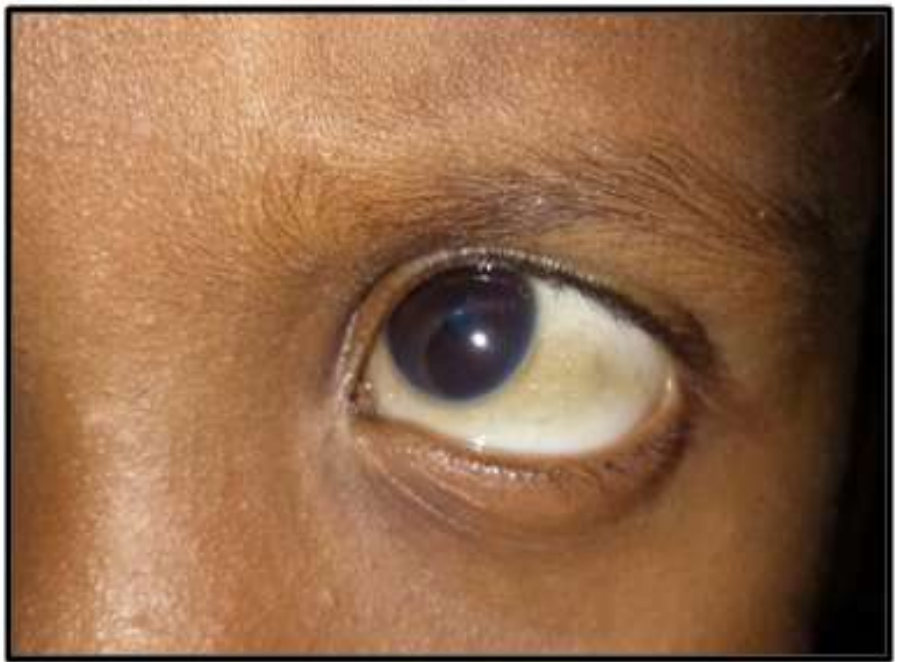

Vitamin A Deficiency (VAD)

Demographic details of patients

\begin{tabular}{|r|l|c|c|c|c|}
\hline $\begin{array}{l}\text { Sr. } \\
\text { No }\end{array}$ & Group & Male & Female & Total & $\begin{array}{l}\text { Mean Age } \\
\text { (Month) }\end{array}$ \\
\hline $\mathbf{1}$ & Vernal Keratoconjunctivitis & 12 & 04 & 16 & 161 \\
\hline $\mathbf{2}$ & Vitamin A Deficiency & 12 & 06 & 18 & 104 \\
\hline $\mathbf{3}$ & Dry Eye & 06 & 14 & 20 & 135 \\
\hline $\mathbf{4}$ & Chemical Burn & 04 & 02 & 06 & 411 \\
\hline
\end{tabular}

Squamous metaplasia and decrease in goblet cell density on impression cytology.

\begin{tabular}{|c|c|c|c|c|c|}
\hline Groups & Grade & $\begin{array}{c}\text { VKC } \\
(n=16)\end{array}$ & $\begin{array}{c}\text { Vitamin A } \\
\text { Deficiency } \\
(n=18)\end{array}$ & $\begin{array}{c}\text { Chemical } \\
\operatorname{Burn}(n=06)\end{array}$ & $\begin{array}{c}\text { Burn }(n=10) \\
\text { Dry Eye }(n=20)\end{array}$ \\
\hline \multirow{4}{*}{$\begin{array}{c}\text { Decrease in Goblet cell } \\
\text { Density }\end{array}$} & No & 6 & 0 & 0 & 0 \\
\hline & Mild & 3 & 0 & 0 & 4 \\
\hline & Mod. & 4 & 0 & 1 & 2 \\
\hline & Severe & 3 & 18 & 5 & 14 \\
\hline \multirow{4}{*}{$\begin{array}{l}\text { Loss of Cell } \\
\text { Cohesion }\end{array}$} & Absent & 4 & 0 & 1 & 0 \\
\hline & Mild & 1 & 0 & 1 & 1 \\
\hline & Mod. & 8 & 12 & 3 & 5 \\
\hline & Severe & 3 & 6 & 1 & 14 \\
\hline \multirow{4}{*}{ Change in $\mathrm{N}: \mathrm{C}$} & Absent & 1 & 1 & 0 & 0 \\
\hline & Mild & 2 & 1 & 1 & 2 \\
\hline & Mod. & 10 & 14 & 3 & 10 \\
\hline & Severe & 3 & 2 & 2 & 8 \\
\hline
\end{tabular}




\begin{tabular}{|l|l|c|c|c|c|}
\hline \multirow{4}{*}{ Keratinizatio } & Absent & 10 & 4 & 0 & 2 \\
\cline { 2 - 6 } & Mild & 1 & 4 & 1 & 2 \\
\cline { 2 - 6 } & Mod. & 5 & 6 & 2 & 10 \\
\cline { 2 - 6 } & Severe & 0 & 4 & 3 & 6 \\
\hline
\end{tabular}

Ratio >1: 4 to pyknotic nuclei with intermediate to enlarge shape ofcells. Few patients showed presence of intraepithelial inflammatorycells which was present in only in this group. These inflammatorycells were elongated in shape and present in between epithelial cells. On Conjunctival biopsy, we noted the clumping of gobletcell in one patient, while the second patient showed the moderatereduction of goblet cell, both the patient showed the presence ofsquamous metaplasia by observing the alteration in N:C ratio and thepresence of keratinisation Dry eye group - Out of the sixty patients in this group, 6 (30\%) weremale and 14 (70\%) female, with mean age of 135 months. All patientsshowed (Table2) moderate reduction to complete absence of gobletcells. In aqueous tear deficiency group all patients showed completeabsence of goblet cells while ineffective resurfacing group showed moderate to occasional presence of goblet cells. In 14/20(70\%)patients showed absence of goblet cells. In this group different gradesof squamous metaplasia was observed, maximum patients showedmoderate to severe grade changeswhile ineffective resurfacinggroup showed mild to moderate changes. In 19/20 (95\%) showedcomplete loss of cell cohesion and cells appeared in isolated conditionalong with the presence of keratinisation in 16/20 (80\%) patients.Themetaplastic cells were enlarged along with the change in N:Cratio in 18/20 (90\%) patients . On Conjunctival biopsy, weobserved a moderate reduction of cells in one patient while the otherpatient showed occasional presence of goblet cells and severe grade ofmetaplasia, by the presence of pyknotic nuclei and anucleated cells. There was marked presence of keratinisation .

Chemical injury group -six patients (4 male and 2 female) were included in this group with mean age of 411 months. five patients (85\%) showed complete absence of goblet cells while in $1 / 6(15 \%)$ patient's occasional presence of goblet cells was seen. Normal epithelial sheet clusters were present in 2/6 (33.33\%) patients with early keratinisation. five patients $(90 \%)$ showed 1:4 N: C ratio to pyknotic nucleus along with enlarged polygonal cell size. Keratinization were present in $5 / 6$ patients $(83.33 \%)$ of moderate to severe grade. On Conjunctival biopsy, we observed the early keratinization with 1:3 ratio of $\mathrm{N}: \mathrm{C}$ in one patient while the other patient showed the 1:4 to : 1:5 N:C ratio with polygonal in shape and enlarge in Size With markedpresence of keratinisation.

\section{Conclusion}

Impression cytology is a very useful, simple, diagnostic and non invasive technique. It is helpful in the early diagnosis, staging and monitoring effects of treatment. Biopsies can be avoided in suspected malignancies and it is useful in follow up of recurrent cases. We therefore recommend that impression cytology may be introduced as a routine clinical practice for all ocular surface disorders

\section{References}

[1]. Tseng SC, Tsubota K (1997) Important concepts for treating ocular surface and tear disorders. Am J Opthalmol 124: 825-835.

[2]. Thoft RA, Wiley LA, Sundarraj N (1989) Themultipotential cells of the limbus. Eye (Lond) 3: 109-113

[3]. Egbert PR, Lauber S, Maurice DM (1977) A simple conjunctival biopsy. Am J Ophthalmol 84: 798-801

[4]. Mc Kelvie P (2003) Ocular surface impression cytology. AdvAnatpathol 10: 328-337.

[5]. Nolan GR (2004) Overview of cytology of OSSN with special reference to impression cytology, ophthalmic pathology for general anatomic pathologists. Pathol International 54: S397-S400.

[6]. Neelima Sharma B.Sc.Hons., N. Kabir B.Sc., Feeroj A. Chauhan M.Sc. SeemaSen MD, SeemaKashyap MD. Impression CytologyRole in Ocular Surface Disorders. DOS Times - Vol. 20, No. 5 November, 2014. 